\title{
Trivium
}

Revue franco-allemande de sciences humaines et sociales - Deutsch-französische Zeitschrift für Geistesund Sozialwissenschaften

29 | 2019

Regards croisés sur le prophète de l'Islam

\section{»König oder Diener«? Die Versuchung des Propheten oder die Wahl eines Modells}

\section{Samuela Pagani}

Traducteur : Michael Adrian

\section{(2) OpenEdition}

\section{Journals}

Édition électronique

URL : http://journals.openedition.org/trivium/6241

ISBN : 1963-1820

ISSN : 1963-1820

Éditeur

Les éditions de la Maison des sciences de l'Homme

Référence électronique

Samuela Pagani, « »König oder Diener «? Die Versuchung des Propheten oder die Wahl eines Modells », Trivium [Online], 29 | 2019, online erschienen am 17 Oktober 2019, abgerufen am 08 September 2020. URL : http://journals.openedition.org/trivium/6241

Ce document a été généré automatiquement le 8 septembre 2020

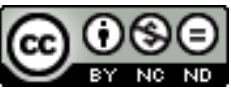

Les contenus des la revue Trivium sont mis à disposition selon les termes de la Licence Creative Commons Attribution - Pas d'Utilisation Commerciale - Pas de Modification 4.0 International. 


\title{
»König oder Diener«? Die Versuchung des Propheten oder die Wahl eines Modells
}

\author{
Samuela Pagani \\ Traduction : Michael Adrian
}

\section{NOTE DE L'ÉDITEUR}

Wir danken Frau Samuela Pagani für die freundliche Genehmigung, diesen Artikel in deutscher Übersetzung zu publizieren.

Nous remercions Mme Samuela Pagani de nous avoir accordé l'autorisation de traduire ce texte pour le présent numéro.

1 In diesem Beitrag möchte ich eine Überlieferung analysieren, die gelegentlich als "Geschichte von der Wahl« (qissat al-takhyîr) ${ }^{1}$ bezeichnet wird. Dieser Überlieferung zufolge fordert ein Engel, der »noch über Gabriel« steht, eine Stimme ohne Namen oder der Herr selbst den Propheten Muhammad dazu auf, sich zu entscheiden, ob er als Prophet ein König oder ein Diener sein wolle. Diese Alternative bildet einen Gegensatz zwischen zwei prophetischen Typen, die beide das traditionelle Bild Muhammads geprägt haben: Als »königlicher Prophet « ist Muhammad der Inbegriff der Souveränität und schließt damit an das Modell des Heiligen Königtums in der Bibel und im Koran an; als »dienender Prophet« verkörpert er das Ideal der Unterwerfung unter Gott, das in der Bibel wie im Koran in der Titulierung »Diener Gottes« oder "Knecht Gottes« zum Ausdruck gebracht wird. Im Koran bezeichnet dieses Beiwort sowohl Propheten, die ihr Königtum (mulk) von Gott erhalten haben, als auch Propheten, die keine Könige waren. ${ }^{2}$ Die Unterscheidung oder vielmehr der Gegensatz zwischen König und Diener wird in der Tradition weiterentwickelt und nimmt wichtige politische und theologische Konnotationen an, die zugleich das Wesen und die Funktion des Propheten betreffen. Die »Erzählung von der Wahl« inszeniert die Spannung zwischen diesen beiden Bestandteilen seines Bilds in Form einer Versuchungsgeschichte. Ganz wie die 
Erzählung von Jesu Versuchung in der Wüste ${ }^{3}$ spiegelt sie eine Debatte über das Wesen und die Funktion des Begründers, die bis in die erste Phase der Gemeinschaft zurückreicht, sich aber im Laufe ihrer Geschichte immer weiter entwickelt hat. In dieser Debatte treffen unterschiedliche typologische Interpretationen der Person des Religionsstifters aufeinander, das heißt unterschiedliche Weisen, ihn in der Heilsgeschichte zu verorten, indem man sein Verhältnis zu den biblischen Figuren erhellt. Die Bestimmung eines Typus kommt der Entwicklung einer Ikonographie gleich, ob diese in Texten oder in Bildern entfaltet wird. Wie wir noch sehen werden, konkurriert die Haltung des Propheten gemäß den in frommen Milieus tradierten Überlieferungen mit einer königlichen Ikonographie, die nicht nur von einzelnen Texten, sondern auch von einigen wenigen Miniaturen bezeugt wird. Diese Typen überdauern die Zeiten und passen sich dabei an immer neue Kontexte an. Am Anfang des 20. Jahrhunderts haben sich diese alten Symbole im Rahmen des modernen Gegensatzes zwischen dem Politischen und dem Religiösen mit neuen Bedeutungen aufgeladen. Kurz nach der Abschaffung des osmanischen »Kalifats« im Jahr 1924 führt der ägyptische Jurist 'Alî 'Abd al-Râziq die »Geschichte von der Wahl« als eines der traditionellen Zeugnisse für die Tatsache an, dass »der Prophet kein König war und die souveräne Macht weder anstrebte noch ersehnte «. ${ }^{4}$ Dass der Prophet kein König sein wollte, heißt für diesen Autor, es sei nicht Aufgabe des Islams, über die Staatsform zu entscheiden. Dies würde die Trennung von Politik und Religion erhärten, die 'Abd alRâziq gegen die aufkommenden Theorien des islamischen Staats verteidigt. Daran muss auch deshalb erinnert werden, weil 'Abd al-Râziq zumeist als Sprachrohr westlicher Konzeptionen betrachtet wird, ohne dass man seine Verwurzelung in seiner eigenen Tradition berücksichtigt. Die traditionelle Darstellung Muhammads als eines »königlichen Propheten« wird hingegen von manchen westlichen Forschern immer noch als Beweis dafür angeführt, dass »die Trennung von Politik und Religion für den Islam keine Existenzberechtigung hat,$^{5}$ ja dass sich der Islam durch eine "außergewöhnliche [...] Verschmelzung « des Politischen und des Religiösen definiert. ${ }^{6}$ Entgegen diesen Schematisierungen zeugt die "Geschichte von der Wahl« von der Komplexität jener traditionellen Darstellung, die man nicht auf eine bestimmte politische Theorie reduzieren kann. Das Bild Muhammads transportiert vielmehr unterschiedliche Konzeptionen des Verhältnisses zwischen beiden Mächten, die von der Verschmelzung über die Einheit in der Differenz bis zur Spaltung reichen.

\section{Die Sîra und die Versuchung der Macht}

2 Bevor wir den Gegensatz zwischen den beiden Figuren des königlichen und des dienenden Propheten in der »Geschichte von der Wahl« untersuchen, wollen wir uns dem Thema der Versuchung der Macht widmen, wie es die überlieferte Erzählung vom Leben des Propheten, die Sira, entfaltet. In drei entscheidenden Momenten taucht dieses Thema hier auf: bei den beiden Prüfungen auf die Echtheit seines prophetischen Anspruchs, denen Muhammad in seinen Auseinandersetzungen mit den Quraisch von Mekka und den Juden von Medina unterzogen wird, und bei der Entscheidung zwischen dieser Welt und der jenseitigen, zu der er in der Stunde seines Todes aufgefordert wird. Wie wir sehen werden, zeigt jede dieser drei Episoden unser Thema in einem anderen Licht. 
3 Nach der Sîra des Ibn Ishâq/Ibn Hishâm laden die ungläubigen Quraisch Muhammad zu Beginn seiner Weissagungen in Mekka zu sich, um ihn in Versuchung zu führen: Wenn es ihm um Geld ginge, würden sie ihn zum reichsten Mann unter ihnen machen; sei Ehre sein Ziel, so wollten sie ihn zu ihrem Ältesten ernennen; sei es aber die Souveränität, dann zu ihrem König (wa in kunta turîdu bihi mulkan mallaknâka 'alaynâ). Sie stellen ihn anschließend vor mehrere Herausforderungen: Er soll durch Wunder beweisen, dass er der Gesandte Gottes ist; er soll seine Gunst und seine Stellung bei Gott vor Augen führen, indem er Ihn bittet, einen Engel zu schicken; oder er soll schließlich »den Himmel stückweise« über sie herabfallen lassen. Muhammad weist diese Versuchungen und Herausforderungen zurück: »Ich tu dies nicht und verlange nichts von Gott für mich [...]. Nicht dafür bin ich euch gesandt worden. « ${ }^{7}$

Diese Erzählung bündelt eine Reihe von Koranversen, in denen die Ungläubigen sich weigern, dem Propheten Glauben zu schenken, weil er lediglich ein Mensch sei wie alle anderen. ${ }^{8}$ Die Quraisch sind vielmehr der Ansicht: „Gott ist zu groß, als dass sein Bote ein Mensch wie wir sein könnte«; ein Bote müsse sich vom Rest der Menschen unterscheiden (yatamayyazu) wie die Engel, die die Ungläubigen anbeten. ${ }^{9}$ Die Sîra ergänzt das Dementi der engelhaften Natur des Propheten im Koran um die Weigerung, ihn als königlich anzusehen, wobei sie dem Thema die Form einer Versuchungsgeschichte verleiht, deren Vorbild die Versuchung Jesu in der Wüste sein könnte. ${ }^{10}$

5 Wie die Geschichte von der Versuchung Christi durch den Teufel informiert uns die Geschichte von der Versuchung Muhammads durch die Quraisch über das Wesen seiner Person und das Ziel seiner Mission - »euch frohe Botschaft und Drohungen (bashîr nadhîr) zu bringen«, erwidert er seinen »Versuchern«: Ich habe euch meine Botschaft übermittelt, es ist an euch, sie anzunehmen oder zurückzuweisen. Nach einer anderen Rezension der Sîra Ibn Ishâqs erscheint Muhammad in dem Moment, als die Quraisch sich dazu verschwören, ihn zu töten, der Erzengel Gabriel und sagt ihm: »Gott hat den Himmel, der Erde und den Bergen befohlen, dir zu gehorchen. Wenn du willst, befehle dem Himmel, ihnen auf den Kopf zu fallen, der Erde, sie zu verschlingen, und den Bergen, sie zu zermalmen." Der Gesandte Gottes aber erwidert: »Ich gebe meiner Gemeinschaft einen Aufschub (u'akhkhir): Vielleicht wendet Gott sich ihnen zu. « ${ }^{11} \mathrm{Im}$ Anschluss an diese Episode wird die biblische Erzählung von der Bestrafung der Rotte des Korah angeführt, in der Mose sich unerbittlich zeigt, und Gott kommentiert: »Meine Diener haben dich angefleht, und du hast sie nicht angehört. Hätten sie sich an mich gewendet, hätte ich sie erhört. «12 Durch seine Nachgiebigkeit und seine Milde zeichnet sich Muhammad hier vor Mose aus und zeigt seine Ähnlichkeit mit Jesus. ${ }^{13}$

6 Muhammads Nachgiebigkeit und Milde passen gut $\mathrm{zu}$ seiner Eigenschaft als verkündender und mahnender Prophet, der von den Seinen abgelehnt und verfolgt wird. Die Verhältnisse ändern sich nach der Hidschra, als er eine von seiner Gemeinschaft anerkannte Herrschaft ausübt und mit der Hilfe von Engeln militärische Siege erringt. Die Natur der Macht des Propheten ist just das Thema der zweiten Versuchungsgeschichte in der Sîra, in der Muhammad mit den Juden Medinas konfrontiert ist. In diesem Rahmen stellt sich der Gegensatz zwischen Prophetie und Königtum in neuem Licht dar. In Medina stellen die Rabbiner Muhammad auf die Probe, indem sie ihn einen Ehebruch beurteilen lassen: Erkennt er auf Steinigung, also die von der Thora vorgeschriebene Strafe, dann ist er ein wahrer Prophet (nabî), verurteilt er aber zu Geißelung, öffentlicher Demütigung und Verbannung, dann ist er 
lediglich ein König (malik). ${ }^{14}$ Indem er sich für die erste Alternative entscheidet, aktualisiert Muhammad das Vorbild Moses und erweckt das mosaische Gesetz zu neuem Leben. ${ }^{15}$ Im Unterschied zur Versuchung von Mekka, die Muhammads Nachgiebigkeit betont und uns über die menschliche Natur des Gesandten unterrichtet, setzt die Versuchung von Medina voraus, dass er eine Machtposition innehat, und klärt uns über deren Charakter auf: Er ist kein König, sondern ein Prophet, weil er keine Gesetze erlässt, sondern lediglich das göttliche Gesetz anwendet. ${ }^{16}$ Muhammad begründet keine Monarchie, sondern eine Nomokratie.

7 In diesen ersten beiden Geschichten ist die Versuchung eine Probe auf die Wahrhaftigkeit von Muhammads Prophetie. Sie antwortet auf einen polemischen Einwand, der den Islam von Geburt an begleitet hat und dem zufolge Muhammad kein echter Prophet ist, sondern ein König. ${ }^{17}$ Anders verhält es sich in der Erzählung vom Tod Muhammads, in der das zurückgewiesene Angebot nicht vom Feind kommt, sondern von Gott, und verlockend auf die treuen Gefährten des Propheten wirkt. In diesem Kapitel der Sira wird das Thema der Wahl dreimal aufgegriffen. Die erste Stelle findet sich gleich zu Beginn, im Abschnitt über den Ausbruch seiner Krankheit. Nach einer von 'Abdallâh b. 'Amr b. al-'Âs geschilderten Überlieferung zieht sich Muhammad eines Nachts zum Gebet in den Friedhof 'al-Baq1' zurück, leistet Abbitte für die im Kampf gefallenen Gläubigen, kündet künftige Streitigkeiten (fitan) an und erklärt schließlich seinem Begleiter, einem Freigelassenen (mawlâ) namens Abû Muwayhiba:

mMir wurden die Schlüssel zu den Schätzen dieser Welt (mafâtîh khazâin al-dunyâ) und das ewige Verweilen in ihr (wa l-khuld fihâ) ${ }^{18}$ und anschließend das Paradies angeboten, und ich wurde vor die Wahl (khuyyirtu) gestellt, mich dafür oder für die Begegnung mit meinem Herrn und das Paradies zu entscheiden.\& Darauf erwidert sein Begleiter: `Ich flehe dich an, nimm die Schlüssel für die Schätze dieser Welt, das ewige Verweilen in ihr und das Paradies! Doch Muhammad entgegnet ihm: 'Nein, bei Gott, Abû Muwayhiba! Ich habe mich für die Begegnung mit meinem Herrn und das Paradies entschieden!«19

Muhammad spielt ein weiteres Mal auf diese Entscheidung an, als er auf seine Kanzel steigt, um seine letzten Worte zu verkünden: "Gott hat einem seiner Diener die Wahl gelassen zwischen dieser Welt und der in Seiner Nähe, und er hat die in Gottes Nähe gewählt.« Abû Bakr bricht in Tränen aus, weil er als einziger versteht, dass Muhammad von seinem unmittelbar bevorstehenden Tod spricht. ${ }^{20}$ Schließlich taucht das Thema der Wahl ein letztes Mal in 'Â'ishas Bericht über den Tod des Propheten auf. ${ }^{21}$

Das Angebot der "Schlüssel zu den Schätzen dieser Welt" sowie das des »ewige[n] Verweilen[s] in ihr « im ersten dieser Texte erinnert an die biblischen Prophezeiungen der Thronbesteigung des Messias-Königs, ${ }^{22}$ die mitunter als Testimonia für die Ankunft Muhammads angeführt werden..$^{23}$ Die Vision vom Angebot der Schlüssel wird darüber hinaus von einer kanonischen Überlieferung zu den Gunstbeweisen gezählt, die dem Propheten vorbehalten sind: "Ich wurde mit der Summe der Worte (jawâmi al-kalim) ausgesandt, ich habe mittels Terror $\left(r u^{\prime} b\right)$ den Sieg erlangt, und während ich schlief, wurden mir die Schlüssel zu den Schätzen dieser Welt gebracht, und man hat sie mir in die Hand gedrückt (utîtu bi-mafâtîh khazẩin al-ard fa-wudi'at fi yadî) «. ${ }^{24}$

In dieser Episode der Sîra weist Muhammad die Gunst jedoch gegen den Wunsch Abû Muwayhibas zurück. Die Reaktion dieses Gefährten hat eine Parallele in den Protesten 'Umars und anderer Gefährten, als sie die Nachricht von Muhammads Tod erhalten. 'Umar bestreitet sie zunächst: 
"Einige Heuchler behaupten, Muhammad sei gestorben, aber bei Gott, Muhammad ist nicht gestorben, sondern er ist zu seinem Herrn gegangen, wie Moses der Sohn Amrams, welcher vierzig Tage von seinem Volke fern geblieben (ghâba) und dann wieder zurückgekehrt ist (raja'a), nachdem man ihn schon tot gesagt hatte, bei Allah, der Gesandte Gottes wird auch wie Moses zurückkehren und denen, welche ihn tot sagten, Hände und Füße abschneiden. $\ll^{25}$

Eine namentlich nicht genannte Gruppe von Gefährten verschließt sich ebenfalls der Nachricht vom Tod des Propheten mit den Worten: »Wie kann es sein, dass er stirbt, bevor er über die Menschen triumphiert hat (wa lam yazhar 'alâ al-nâs)«, das heißt bevor er die Welt erobert hat? Im Unterschied $\mathrm{zu}$ 'Umar vergleichen diese Gefährten Muhammad mit Jesus und sagen, dass er wie dieser »aufgefahren« sei und "wiederkehren werde" (rufi'a [...] wa-la-yarji'anna). ${ }^{26}$

In der Erzählung der letzten Tage Muhammads dient das Motiv der Wahl dazu, den Umständen seines Todes einen Sinn zu geben. Die von Ibn Hishâm bearbeiteten Überlieferungen zielen auf eine Bestätigung der Sichtweise, die sich schließlich bei den Sunniten durchgesetzt hat: Der Prophet hat weder einen Erben noch ein Erbe hinterlassen und formell keinen Nachfolger eingesetzt, auch wenn er durch verschiedene Zeichen seine Präferenz für Abû Bakr gezeigt hat. Ganz bewusst wird die Geschichte der Wahl als Motto einem Kapitel vorangestellt, das diese Probleme anspricht. Durch seinen Verzicht erhebt sich Muhammad über die weltlichen Wechselfälle seiner Gemeinschaft, die an der Schwelle zu ruhmvollen Eroberungen und zum Abgrund der Bürgerkriege steht. Muhammad ist der Gründer der »besseren Gemeinschaft«, doch ist er nicht der erste »König« des islamischen Reichs. Durch seine Wahl des Todes erweist er sich als einer wie Mose und Jesus, die Jünger hinterlassen, aber keine Dynastien begründet haben. Wie Mose, der stirbt, bevor er das gelobte Land betritt, stirbt Muhammad vor den Eroberungen ${ }^{27}$ und begegnet dem Engel des Todes. ${ }^{28}$ Zudem erinnert die Reaktion Abû Muwayhibas an Petrus' Bestürzung angesichts der Leidensankündigung Jesu..$^{29}$

Das Kapitel über die letzten Tage des Propheten in Ibn Hishâms Sîra endet mit der Kontroverse zwischen Abû Bakr und 'Umar über die Realität seines Todes. Abû Bakr, der als einziger die Anspielung auf die »Wahl« des Dieners in Muhammads letzter Rede versteht, erweist sich durch seine nüchterne Reaktion auf den Tod des Propheten und seine standhafte Entgegnung auf 'Umars Proteste als geeignetster Mann, um die Gemeinschaft als getreuer »Nachfolger« ohne jede extravaganten Ansprüche zu führen. 'Umar hingegen, der so weit geht, von der »Verborgenheit« und »Rückkehr« des Propheten zu sprechen, werden aufgrund seiner Eroberungen, zumal der Jerusalems, die ihn wie einen David erscheinen lässt, messianische Züge zugeschrieben. ${ }^{30}$ Die an den Anfang des Kapitels gestellte Wahl Muhammads gibt Abû Bakr von vornherein Recht gegenüber 'Umar und bestätigt zugleich die überlegenen Verdienste des Ersteren. Muhammads Entsagung funktioniert somit in diesem Zusammenhang wie eine Lektion für diejenigen seiner treuesten Gefährten, die von den Reizen dieser Welt in Versuchung geführt werden könnten. In einer Variante des Hadiths der Wahl richtet sich diese Lektion an 'Umar selbst. Eines Tages vergleicht dieser mit Bedauern die Schmucklosigkeit des Propheten mit dem Pomp der Chosraus und Cäsaren. Muhammad korrigiert ihn, indem er ihm erzählt, dass er sich dafür entschieden hat, ein dienender Prophet zu sein. ${ }^{31}$

14 Gegen die Vorstellung, Muhammad sei der Gründer eines universellen Reichs gewesen, des letzten vor dem Tag des Gerichts, zeigt seine "Wahl« des Todes seine 
Übereinstimmung mit anderen biblischen Vorbildern. Im Unterschied zur polemischen Auseinandersetzung mit den Feinden geht es hier nicht darum, die Echtheit von Muhammads Prophezeiungen zu verteidigen, sondern den letzten Sinn seiner Mission zu definieren und zu bestimmen, wer sein treuester Erbe ist. Muhammad könnte von dem Angebot der "Schlüssel zu den Schätzen dieser Welt« Gebrauch machen, ohne seinem Status als wahrer Prophet zu widersprechen, würde sich in diesem Fall aber eines niedrigeren Rangs erfreuen, als er ihm in Wirklichkeit zukommt.

Die zahlreichen Varianten der Geschichte von der Wahl lassen sich auf drei Themen zurückführen: die Erniedrigung des Königs, das sich Kleinmachen seines Schutzengels und die Lobpreisung des Dieners. Sie sollen im Folgenden der Reihe nach untersucht werden.

\section{Die Erniedrigung des Königs}

Die alten Sammlungen von Überlieferungen zur Askese (zuhd) führen die Geschichte der Wahl hinsichtlich zweier Aspekte von Muhammads Verhalten an: seiner Tischsitten und der Art und Weise, wie er von seiner Kanzel (minbar) predigt. Auf die Haltung des Propheten kommt es nicht nur an, um eine gute Praxis (sunna) zu etablieren, sondern auch, weil sie seinen prophetischen Typus charakterisiert. Dies tritt deutlich bei Ibn Sa'd (gest. 230/845) hervor, bei dem das Kapitel über die "Essgewohnheiten« ( $m a^{\prime} k a l$ ) des Propheten auf zwei Kapitel folgt, von denen eines seine Ankündigung in der Thora und im Evangelium und das andere seinen Charakter (khuluq) beleuchtet.

Ibn Sa'ds Kapitel über die Ankündigung Muhammads in der Thora und im Evangelium ${ }^{32}$ versammelt eine Reihe von Überlieferungen, die die Beschreibung eines "Dieners Gottes« in Jesaja 42 paraphrasieren. Die Beschreibung des »Dieners« als jemanden, der nicht schreien und nicht rufen und dessen Stimme folglich auf den Gassen nicht $\mathrm{zu}$ hören sein wird (Jesaja 42,2), ist eines der wichtigsten biblischen Zeugnisse für den letzten Propheten. ${ }^{33}$ Noch bevor sie in systematischer Form in die Werke über die "Zeichen der Prophetie» eingearbeitet werden, spielen diese biblischen Verkündigungen bereits in der ältesten islamischen Tradition eine wichtige Rolle..$^{34} \mathrm{Ibn}$ Sa'd schildert die biblische Verkündung des letzten Propheten in der Version Ka'b alAhbârs (gest. ca. 32/652) sowie in der des Gefährten 'Abdallâh b. 'Amr b. al-'Âs, der zugleich der Übermittler der Erzählung vom Friedhof 'al-Baqî́ ist. Dieser letzten Version zufolge erwidert besagter Gefährte auf die Frage nach der Beschreibung Muhammads in der Thora:

»Er wird in der Thora auf die gleiche Weise beschrieben wie im Koran: ^O Prophet, Wir haben dich entsendet als einen Zeugen und einen Freudenboten und Warner $(33,45)$. In der Thora nun aber steht: $>$ Prophet, Wir haben dich entsendet als einen Zeugen, einen Freudenboten, einen Warner, eine Zuflucht für die Heiden. Du bist mein Diener und mein Gesandter, ich habe dich genannt >der Vertrauenerweckende ( $a l-$ mutawakkil). Er ist weder streng noch brutal (laysa bi-fazz wa lâ ghalîz), er schreit nicht auf den Plätzen (wa lâ sakhkhâb bi-l-aswâq), er wehrt Böses nicht mit Bösem ab (wa lâ yadfa'u al-sayyi'a bi-l-sayyi'a), ${ }^{35}$ sondern er verzeiht und vergibt (wa lâkin ya'fû wa yaghfiru). « ${ }^{36}$

Bescheidenheit, Sanftmut, Mitleid, diese entscheidenden Merkmale des letzten von der Bibel verkündeten Propheten entsprechen exakt dem Charakter Muhammads. Dadurch, dass Ibn Sa'd das Kapitel über Muhammads Charakterzüge (akhlâq) im Zuge seiner redaktionellen Bearbeitung unmittelbar an das Jesaja-Zitat anschließt, legt er nahe, 
dass die Figur des "Dieners" dem inneren Habitus und den natürlichen Anlagen des Propheten am ehesten entspricht. Die bevorzugten Zeugen, um diesen Habitus zu beschreiben, sind die Gefährten, vor allem jene, die ihn privat gekannt haben: seine Frauen und seine jungen Diener. Die Gemahlinnen des Propheten werden insbesondere dazu befragt, welchen Charakter er »zu Hause« (fi baytihi) zeigte, »wenn er sich zu sich zurückzog" (idhâ khalâ fì baytihi), sowie zu "seinem Verhalten in der Intimität» ('amaluhu fíl-sirr)..$^{37}$

19 Zum »häuslichen« Charakter des Propheten befragt, wiederholt 'Â'isha fast Wort für Wort die Beschreibung der Thora:

»Charakterlich war er der beste Mensch. Er war nicht vulgär und betrug sich nicht unschicklich (lam yakun fâhishan wa lâ mutafahhishan), er schrie nicht auf den Plätzen (wa lâ sakhkhâb fî l-aswâq), und er vergalt Böses nicht mit Bösem (wa lâ yajzî bi-l-sayyi'a mithlahâ), sondern er verzieh und vergab (wa lâkin ya'fû wa yasfahu). «"38

Durch diese besonderen Merkmale unterscheidet sich der »Diener« vom "Tyrannen«: »Der Prophet hatte Eigenschaften, die es bei Tyrannen nicht gibt (kânat l-nabî khisâl laysat fíl-jabbârîn)«, stellt der Nachfolger (tâbi ${ }^{39}{ }^{39}$ Hamza b. 'Abdallâh b. 'Utba fest. ${ }^{40}$

Der Begriff jabbârûn verdient einen kurzen Exkurs. In unserem Zusammenhang ist der jabbâr, wie der König, der Gegenbegriff zum »Diener «. ${ }^{41}$ Die negative Bedeutung, die unsere Traditionen mit diesem Ausdruck verbinden, entspricht dem koranischen Gebrauch. Im Koran sind die jabbârûn "Hünen" (K 5,22), und jabbâr heißt im Allgemeinen »Tyrann" oder "gewalttätig« (z. B. 11,59; 14,15). ${ }^{42}$ Johannes der Täufer und Jesus werden dafür gepriesen, dass sie keine jabbâr sind (19,14 u. 32), und Gott erinnert Muhammad daran, er solle kein jabbâr sein, weil seine Mission nicht darin bestehe, die Menschen in seine Gefolgschaft zu zwingen $(50,45)$. Tatsächlich ist Al-Jabbâr ein göttlicher Name $(59,23)$, den sich der Mensch nur auf eigene Gefahr aneignet. Fakhr alDîn al-Râzî erläutert: »Man sagt von einem stolzen und hochmütigen Menschen, dass er jabbâr ist, wenn es ihm an Demut fehlt und er sich vor niemandem beugt. Dieser Name gebührt zu Recht Allâh. « ${ }^{43}$

22 Allerdings kann das Attribut jabbâr auch im positiven Sinne auf den Menschen angewandt werden. Dies gilt besonders für die messianischen Prophezeiungen der Bibel, die die islamischen Quellen als Ankündigungen von Muhammads Erscheinen betrachten. Hier übersetzt das arabische jabbâr das hebräische gibbor (»mächtig", »Held«):

»Der Herr zieht in den Kampf wie ein Held (ka-l-jabbâr), er entfacht seine Leidenschaft wie ein Krieger.«44

"Gürte, du Held (ayyuhâ l-jabbâr), dein Schwert um die Hüfte, denn deine Gesetze und deine Regel (sunna) hängen an der Angst, die dein rechter Arm einflößt.« ${ }^{45}$

'Alî al-Tabarî (3./9. Jhdt.) bezieht diese beiden Bibelstellen auf Muhammad und argumentiert, dass die göttlichen Attribute hier ein menschliches Wesen bezeichnen. ${ }^{46}$ Auch Qastallânî (gest. 923/1517) bezieht Psalm 45,4 auf Muhammad und sieht in ihm »ein ausdrückliches geschriebenes Zeugnis der Tatsache, dass Muhammad eine sharia und eine sunna bringt und dass sie durch sein Schwert begründet werden. Was den jabbâr betrifft, so ist er derjenige, der die Menschen mit dem Schwert in rechter Weise zwingt (yujbiru) und durch Zwang (jabr) vom Unglauben abbringt.« ${ }^{47}$

Diese Vorrechte Muhammads entsprechen einer der Definitionen des göttlichen Namens al-Jabbâr: 
"Al-jabbâr ist der, der dazu zwingt, etwas Bestimmtes zu machen, das heißt dass er einen dazu zwingt, das zu machen, was wer will. Man sagt: Der Sultan hat jemanden gezwungen, seinen Befehl auszuführen, wenn er ihn dazu gezwungen hat, etwas zu tun, was ihm zuwider war. Du musst wissen, dass jemanden in dieser Bedeutung dazu zu zwingen, das zu tun, was ihm zuwider ist, stärker ist, als ihn bloß zu etwas zu zwingen oder zu bringen. [...] In diesem Sinne kennzeichnet al-jabbâr Allâh als Jenen, der die Geschöpfe dazu zwingt, das zu tun, was er beschlossen hat, und sie dazu drängt, ob sie wollen oder nicht. « $^{48}$ unmittelbaren visuellen Eindruck von seinem prophetischen Typus. Ihre Symbolik wird 
von dem der Bibel entlehnten Gegensatz zwischen dem »Diener« oder dem »Propheten« auf der einen Seite und den »Königen« oder »Tyrannen« auf der anderen beherrscht: Während auf den Fersen hockend zu essen, in ständiger Bereitschaft, sich wieder zu erheben, der Essgewohnheit des »Dieners « entspricht, ${ }^{56}$ ist mit aufgestützten Ellbogen zu essen »die Essweise der Könige (akl al-mulûk)« oder Tyrannen (jabbârûn); verabscheuungswürdig ist sie, "weil sie dem Gebaren jener entspricht, die ihre Größe zeigen wollen (al-muta'azzimîn), indem sie das Vorbild (asl) der persischen Könige nachahmen. ${ }^{57}$

31 Eine andere Serie von Überlieferungen mit pietistischer Tendenz, in denen das Hadith der Wahl auftaucht, gilt dem Gebrauch des Stabs in der Predigt. Auch in diesem Fall finden wir die Geschichte von der Wahl in Verbindung mit Überlieferungen, in denen die Aufgabe dieser Praxis als Folge einer Ermahnung durch einen Engel oder durch Gott dargestellt wird:

"Gabriel oder ein anderer Engel erschien dem Propheten, als dieser einen Zeigestock (qadîb) ergriff. Er sagte ihm: ১Zerbrich nicht die Köpfe (qurûn, wörtlich Hörner) deiner Gemeinschaft (umma)! « ${ }^{58}$

"Der Prophet nahm einen Palmzweig ('asîb min nakhl), um die Leute zum Schweigen zu bringen. Da offenbarte ihm Gott: \O Muhammad, zerbrich nicht die Köpfe (qurûn) deiner Gemeinschaft! Seitdem wurde der Prophet nicht mehr mit dem Zweig gesehen. $\ll^{59}$

»Ibn Jurayj (gest. 150/767) hat gesagt: Ich habe 'Atâ'60 gefragt: >Hat sich der Prophet, wenn er predigte, auf einen Stab ('asâ) gestützt?` >Ja, sagte er, er hat sich darauf gestützt.، Ibn Jurayj sagte auch: 'Umar b. 'Atâ' hat mir berichtet: >Der Prophet bediente sich eines Palmzweigs ohne Blätter ('asîb min jarîd al-nakhl), um die Leute zum Schweigen zu bringen und ihnen Zeichen zu geben. Da offenbarte ihm Gott: 〉O Muhammad, warum zerbrichst du die Köpfe (qurûn) deiner Schäflein (ra'iyya)?^ Also warf er ihn weg. Dann kamen Gabriel und Michael zu ihm, und Michael sagte: \Dein Herr gibt dir die Wahl, ein königlicher Prophet oder ein dienender Prophet zu sein. Der Prophet blickte zu Gabriel, der ihm mit der Hand ein Zeichen gab, sich zu erniedrigen. Da antwortete der Prophet: `Zweifellos ein dienender Prophet! A Also sagte Gabriel: `Du bist der Fürst der Söhne Adams (sayyid walad Âdam), du bist der erste, für den sich die Erde öffnen wird (tanshaqqu 'anhu al-ard) [bei der Wiederauferstehung], und der erste derjenigen, die Fürbitte einlegen werden (awwal man yashfa $u$ ). $\ll^{61}$

Diese letzte Überlieferung reiht zwei ursprünglich vermutlich unabhängige Geschichten aneinander: In der ersten wird der Prophet aufgefordert, eine abstoßende Praxis aufzugeben; in der zweiten unterbreitet ihm Michael die Wahl zwischen den beiden prophetischen Modellen, und Gabriel rät ihm. Dass hier als erster Engel Michael auftritt, ist bemerkenswert, denn für gewöhnlich ist dieser Engel entweder namenlos, oder er wird mit Isrâfîl identifiziert. Der Schluss mit der Ankündigung der Fürbitte und dem eschatologischen Triumph des Propheten verändert den Tenor der Überlieferung: Die Betonung liegt nicht mehr auf der Korrektur des Propheten, sondern auf dem Lohn, den er dafür enthält, dass er freiwillig auf das Königtum verzichtet. Durch diesen eschatologischen Ausgang hat das Hadith nicht die Funktion, eine sunna zu begründen, sondern den einzigartigen Status von Muhammad zu beglaubigen.

Allem Anschein nach zielen die Überlieferungen, in denen der Prophet durch eine Ermahnung oder seine eigene Wahl dazu veranlasst wird, sich nach der sunna des »Dieners« zu richten, auf die Korrektur einer konkurrierenden Darstellung seiner Person, die mit einer königlichen Bildlichkeit verbunden ist. Die Darstellung Mohammeds, wie er mit einem Stab versehen auf seiner Kanzel sitzt, war ein 
bedeutender Bestandteil dieser Bildlichkeit. ${ }^{62}$ Dem hielten die frommen Traditionisten das Bild eines Propheten entgegen, der nicht nur auf dem Boden saß und aß, sondern seinen minbar auch nie als Sitzgelegenheit verwendete. ${ }^{63}$

Der minbar und der Zeigestock (qadîb) waren Insignien der Hoheitsgewalt der Kalifen. ${ }^{64}$ Seit der Zeit der Umayyaden symbolisierte die Weitergabe dieser beiden Objekte, die dem Propheten gehört haben sollen, zusammen mit seinem Siegel und seinem Mantel die Kontinuität zwischen den Kalifen und Muhammad. ${ }^{65}$ Damit waren beide ein Zeichen für die Erbschaft des Propheten und zugleich eng mit der monarchischen Macht im antiken und spätantiken Nahen Osten verbunden. ${ }^{66}$

In der klassischen sunnitischen Tradition wird das Thema von Muhammads Verzicht mitunter antischiitisch gewendet. So bestreitet der malikitische Jurist Hammâd b. Ishâq (gest. 267/880) das Recht von Muhammads Tochter Fâtima auf die Erbschaft von Ländereien Fadaks, die zur Beute aus dem Feldzug gegen die Oase von Khaybar gehören, und behauptet, der klarste Beweis gegen die Ansprüche der Schiiten bestehe in Muhammads Weigerung, die "Schätze der Erde« anzunehmen. Diejenigen, die die Güter, über die Muhammad verfügte, für ein persönliches Vermögen hielten, das seine Angehörigen erben könnten, würden aus ihm einen »königlichen Propheten« statt eines »entsagenden Propheten « (nabî zâhid) machen. Muhammad aber als »einen der Propheten, die die Könige der Welt waren (ahad mulûk al-dunyâ min al-anbiyấ)«, zu betrachten, heiße, seine Würde zu verletzen (ta'ana). ${ }^{67}$ Der Rechtsgelehrte bezieht so Position im Hinblick auf eine andere berühmte Kontroverse, in der sich Abû Bakr am Tag nach dem Tod des Propheten 'Alî widersetzt hatte. Entgegen den Forderungen Fâtimas und Abbâs' hatte Abû Bakr an ein Hadith von Muhammad appelliert: "Wir haben keine Erben; was wir hinterlassen, ist zum Almosen bestimmt." 'Alî wiederum hatte ihm mit einem Koranzitat entgegnet: „Und Salomo beerbte David. «68

Die Monarchie Davids und Salomons, der Paradebeispiele für den Typus des »königlichen Propheten" in der islamischen Tradition, stellte dabei nicht nur für die Anhänger 'Alîs, sondern seit den Umayyaden auch für die Kalifen das Modell der Verschmelzung von königlicher und religiöser Macht schlechthin dar. ${ }^{69}$ Die Übereinstimmung Muhammads mit diesem prophetischen Typus ist ein Gemeinplatz der klassischen politischen Lehre. ${ }^{70}$ Seltene Miniaturen, die Muhammad mit überkreuzten Beinen auf dem Thron sitzend zeigen und die ab dem 13. Jahrhundert an türkischen und persischen Höfen entstanden sind, belegen die Fortdauer dieses Modells nach dem Ende des abbasidischen Kalifats. ${ }^{71}$

Die Verzichtenden der Gründungsphase ${ }^{72}$ beschränken sich nicht darauf, im Namen der Sunna königliche, profanen Modellen entlehnte Gebräuche zurückzuweisen. Sie gehen vielmehr so weit, die Figur des David abzuwerten: Alten Korankommentaren mit pietistischer Tendenz zufolge ist dieser kein khalifa, sondern ein malik, weil er Blut vergossen hat. ${ }^{73}$ Die Überlieferungen, denen zufolge Muhammad die Anweisung erhält, seine königliche Haltung aufzugeben, können mit der Szene von König Davids Reue verglichen werden. In der christlichen Ikonographie wird die Szene der Erniedrigung Davids manchmal als Abstieg des Königs von seinem Thron dargestellt. So sieht man in der Miniatur eines byzantinischen Psalters aus dem 10. Jahrhundert, wie David, zur Linken auf seinem Thron sitzend, die Vorwürfe Natans anhört, ${ }^{74}$ während der König sich rechts auf dem Bild in der Geste des Bereuenden zur Erde niederbeugt. ${ }^{75}$ 


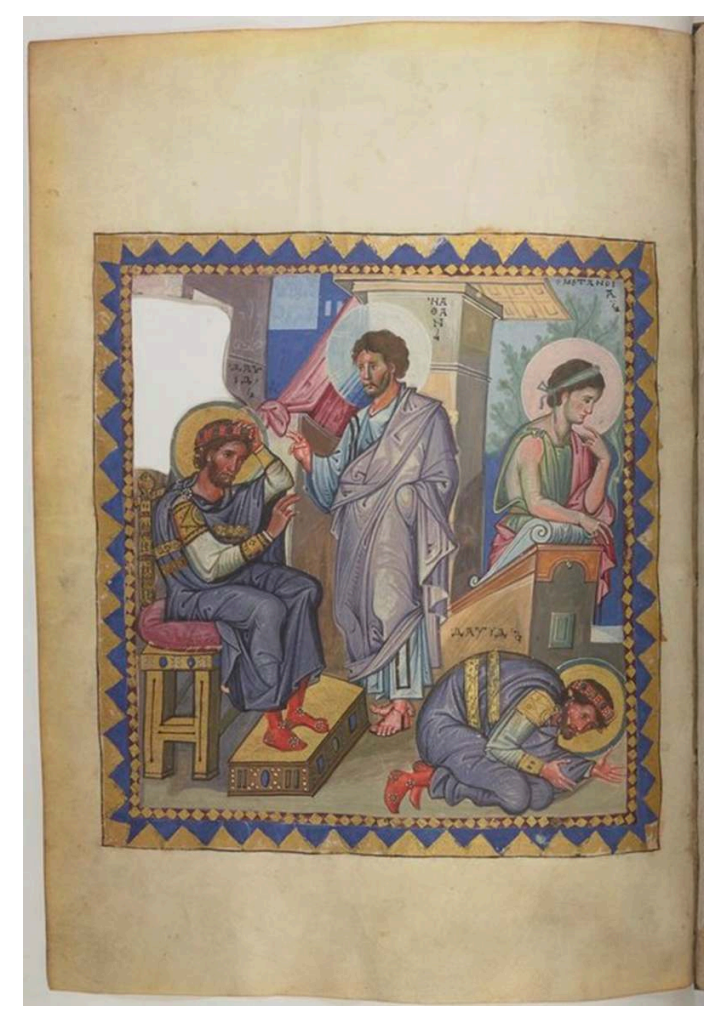

David pénitent, Ms. Grec 139, f. 136v.

BIBLIOTHÈque NATIONALE DE FRANCE, DÉPARTEMENT DES MANUSCRITS, DIVISION OCCIDENTALE

Gilbert Dragon hat im Rahmen seiner Analyse dieses Motivs in der byzantinischen Ideologie gezeigt, dass die Demütigung des Kaisers dem Vorbild der Demütigung des biblischen Königs folgt, jedoch nicht immer dieselbe Bedeutung hat. Auf der einen Seite kann sie zur Veranschaulichung der Theorie der "zwei Mächte« dienen und dem Souverän jedes Priesterprivileg absprechen. Dies ist der Fall bei der Konfrontation zwischen dem Bischof Ambrosius von Mailand und Kaiser Theodosius I., nachdem dieser ein Massaker an aufständischen Einwohnern Thessalonikis hat verüben lassen. Hier wirft der Bischof wie ein neuer Natan dem Kaiser seine Verbrechen vor und verwehrt ihm den Zugang zur Kultstätte mit dem Verweis, dass »der Purpur Kaiser macht, aber keine Priester « ${ }^{76}$ Auf der anderen Seite wurde die Reue des Souveräns als ein »kaiserlicher Akt« verstanden, durch den der Kaiser, der seine Fehler anerkannte und sich vor dem "König der Könige« niederwarf, sich David gleich als ein »Diener Gottes « und nicht als "Tyrann" erwies, und zwar derart, dass die theatralische Reue des Souveräns sich in eine Apotheose verwandelte. ${ }^{77}$

Dies ist auch im Koran der Fall, wo David nach seiner Niederwerfung unmittelbar von Gott als khalifa, als sein Stellvertreter eingesetzt wird. ${ }^{78}$ Die Reueszene im Koran unterscheidet sich durch die Abwesenheit des Propheten Natan. David, der zugleich Diener und König ist ${ }^{79}$ bedarf keines weiteren Repräsentanten Gottes, um in seinen Fehlern korrigiert und in seinen Funktionen anerkannt zu werden. "Diener«, das Beiwort des davidischen Königs in den Psalmen, ist auch ein Titel, mit dem sich die umayyadischen Kalifen schmückten, ${ }^{80}$ die ohne jede priesterliche Vermittlung zu ihren Ämtern gelangten, weil sie selbst beide Mächte verkörperten. ${ }^{81}$ Die pietistische Tradition hingegen räumt Natan in gewisser Weise seinen Platz wieder ein. In einem exemplarischen Dialog fragt 'Umar Muhammads persischen mawlâ Salmân: »Bin ich ein 
König oder ein Kalif?« Salmân gibt ihm eine Antwort, die ihn in Tränen ausbrechen lässt: »Wenn du die islamischen Länder mit einem Dirham besteuert hast, oder mehr oder weniger, und diesen Dirham zu Zwecken verwendet hast, die dem Gesetz

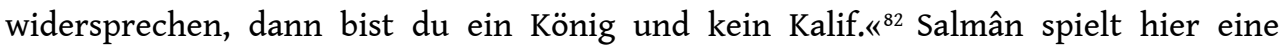
ähnliche Rolle wie die israelitischen Propheten, so wie sie in den islamischen Bibelerzählungen vorkommen: Sie sind nicht selbst Könige, sondern Berater und sittliche Aufseher von Königen. ${ }^{83}$

Obwohl die pietistische Kritik des Königtums tiefe Spuren in der klassischen sunnitischen Tradition hinterlassen hat, konnte diese Tradition die Abwertung der Figur des königlichen Propheten nicht gutheißen, ohne die Legitimität der islamischen Macht und ihre Begründung in divinis in Frage zu stellen. Ibn Taymiyya stellt in seinem Kommentar zum Hadith der Wahl fest, dass er eine »Missbilligung des Königtums" (dhamm al-mulk) impliziert, ${ }^{84}$ gibt sich aber alle Mühe, deren Tragweite abzuschwächen. Die Überlegenheit des Dienergesandten über den Prophetenkönig habe $\mathrm{zu}$ Übertreibungen geführt, »bis an den Punkt, dass einer von den Leuten des Buches die Prophetie Davids und Salomons untergraben hat (ta'ana), genauso wie viele Leute die Autorität der Mächtigen und der Reichen untergraben $~_{.85}$ Das ist falsch, merkt Ibn Taymiyya an, denn die Figuren Josef, David und Salomon beweisen, dass man gleichzeitig König und Prophet sein kann. Genauso kann man zugleich König und Kalif sein. ${ }^{86}$ Das biblische Königtum zu rehabilitieren läuft faktisch darauf hinaus, die Legitimität der Umayyaden zu verteidigen. ${ }^{87}$

41 Ibn Taymiyya bietet eine originelle Lektüre des Hadiths der Wahl, in der er, statt König und Diener in einen scharfen Gegensatz zu stellen, eine dreifache Unterscheidung vornimmt. Für ihn gibt es drei Arten von Propheten: jene, denen man weder Glauben schenkt noch Gehorsam schuldet und die keinerlei Macht ausüben, sowie jene, denen man gehorcht und die eine Herrschaft ausüben. Diese Letzteren wiederum unterteilen sich in zwei Kategorien: den Dienergesandten ('abd rasûl), der nicht das Gesetz begründet, sondern das Buch Gottes anwendet, und den Prophetenkönig (nabî malik), der berechtigt ist, zu gebieten, was er will, wie Salomon. Muhammad gehört, wie Mose, zur ersten Kategorie. ${ }^{88}$

Andere Theologen erkennen eine Entsprechung zwischen Muhammad und dem Typus des königlichen Propheten, relativieren aber ihre Bedeutung. Mâwardî schreibt, dass Muhammad, wie andere Prophetenkönige auch, den Dschihad mit dem Schwert führt und diese Gewalt nötig ist, weil »die bösen Geister nur durch Terror (rahba) abzubringen sind « ${ }^{89}$ Er erläutert andererseits, dass Muhammad die Vergebung der Gewalt vorzieht, wenn er die Wahl hat, sogar im Rahmen seiner individuellen Rechte. ${ }^{90}$ Im selben Geist erläutert Qastallânî: Wenn es heiße, Muhammad sei "weder hart noch brutal«, wie in der Verkündigung Jesajas, die K 3,159 entspricht, so betreffe dies die "edle Natur $\left(t a b^{c}\right)$, getreu der er geschaffen worden sei (jubila 'alayhi)«, oder sein Verhältnis zu den Gläubigen; werde ihm hingegen aufgetragen, hart zu sein, wie in K 9,73, betreffe dies seine Pflicht zur Korrektur ( $m u^{\prime}$ âlaja) oder sein Verhältnis zu den Ungläubigen. ${ }^{91}$ Nach einem Schema, das sich, wie wir oben gesehen haben, bei Ibn Sa'd abzeichnet, werden die Eigenschaften des "Königs" und die des "Dieners" dem öffentlichen Raum respektive der Privatsphäre zugeordnet, ja sogar der äußeren und der inneren Dimension. Der Gegensatz zwischen diesen Eigenschaften wird so durch eine räumliche Metapher dargestellt, in der die beiden Gegenpole nebeneinander bestehen können, ohne dass der eine einen Vorrang gegenüber dem anderen hätte - 
anders als bei der Unterscheidung zwischen den beiden Typen des verfolgten Propheten und des siegreichen Propheten, die durch den Übergang von der mekkanischen zur medinischen Periode chronologisch voneinander getrennt werden.

\section{Das sich Kleinmachen des Engels}

43 In der Version, die wir jetzt untersuchen wollen, ist die Figur, die sich erniedrigt, nicht Muhammad, sondern Gabriel. Diese Version wird manchmal in eine Himmelfahrtserzählung eingebaut:

"Der Prophet hatte sich gerade mit seinen Gefährten versammelt, als Gabriel ihm auf die Schulter klopfte. >Dann<, sagte der Prophet, ,führte er mich zu einem Baum, an dem sich so etwas wie zwei Vogelnester befanden. Kaum nahmen wir Platz, er auf der einen Seite, ich auf der anderen, als der Baum wuchs, bis er den Horizont ausfüllte und uns so weit nach oben beförderte, dass ich mit ausgestreckter Hand den Himmel hätte berühren können. An diesem Punkt wurde eine Leine losgelassen, und das Licht senkte sich (duliya bi-sabab fa-habata al-nûr). Gabriel wurde ohnmächtig wie ein Bettvorleger (ka'annahu hils), ${ }^{92}$ wodurch mir deutlich wurde, dass er noch mehr Angst hatte als ich. Da wurde mir offenbart: ^Dienender Prophet oder königlicher Prophet? Denn ins Paradies kommst du [in jedem Fall] ( $f a-$ ilâ al-janna mâ anta).` Gabriel gab mir im Liegen (mudtaji') ein Zeichen: gewiss dienender Prophet! « ${ }^{93}$

Varianten hiervon finden sich in den Sammlungen kosmologischer oder angelologischer Überlieferungen:

»Als der Gesandte Gottes bei Gabriel war und von Angesicht zu Angesicht (yunâjîhi) mit ihm sprach, riss der Horizont des Himmels auf. Gabriel machte sich ganz klein, zog Arme und Beine an seinen Körper und duckte sich auf den Boden (yatadâ'al wa yadkhul ba'duhu fí ba'd wa yadnû min al-ard). Da erschien ein Engel vor dem Gesandten Gottes und sagte zu ihm: >O Muhammad, dein Herr grüßt dich und lässt dich wählen, ob du ein königlicher Prophet oder ein dienender Prophet sein willst. Der Gesandte Gottes erzählte: Gabriel gab mir einen Wink mit der Hand, mich zu erniedrigen. Ich verstand, dass er mir einen Rat gab, und antwortete: >Dienender Prophet! Dann fuhr dieser Engel zum Himmel auf, und ich sagte: `O Gabriel, ich wollte dich befragen, aber der Zustand, in dem ich dich gesehen habe, hat es mir erübrigt, dir die Frage zu stellen. Wer ist er, o Gabriel? ‘Er ist Isrâfîk, sagte er. >[...] Ich dachte nicht, dass er herabgestiegen wäre, bevor die letzte Stunde gekommen ist. Ich habe mich nur deshalb so kleingemacht, wie du es gesehen hast, weil ich fürchtete, die letzte Stunde sei gekommen. « $^{94}$

Das besondere Merkmal dieser Versionen besteht darin, dass Gabriel sich nicht damit begnügt, Muhammad mit einem Wink zu raten, sondern sich vor einem Engel, der über ihm steht, niederduckt und zusammenkauert. Durch seine Erniedrigung führt Gabriel Muhammad die richtige Antwort vor, ${ }^{95}$ bringt aber zugleich auch seine eigene Furcht zum Ausdruck. Das Bild des »sich Kleinmachens« kehrt - ohne das Motiv der Wahl - in einer persischen Variante der Erzählung von der Himmelfahrt (mi'râj) des Propheten wieder: Anders als Muhammad »beschränkt« sich Gabriel sukzessive, bis er an ein für ihn unerreichbares Maß stößt:

"Gabriel wurde - mit seiner großen Kraft, durch die er mit einem einzigen Flügel Lots Land niederreißen konnte, ohne dass ihm etwas passierte - so klein wie ein Spatz. Muhammad sagte zu ihm: `Lass uns noch einen Schritt weiter gehen.` Gabriel machte noch einen Schritt, und er wurde so klein wie eine Mücke. [...] Was hat dies zu bedeuten? Was wird trotz seiner Erhabenheit nach diesen zwei Schritten aus 
Gabriel? Wie soll er, der nicht fähig war, den Ungehorsam der Sünder zu ertragen,

für sie fürbitten? $«^{96}$ der Knechtschaft mit der Ankündigung seines eschatologischen Triumphs belohnt: »Mein Herr machte mich zum Lohn dafür, dass ich mich vor ihm erniedrigt habe, zum Fürsten der Söhne Adams, dem ersten, für den sich die Erde öffnen wird, und zum ersten Fürsprecher. ${ }^{103}$ Wie wir oben bereits sahen, taucht dieses Thema auch in einer "hybriden" Tradition auf, die das Motiv der Korrektur des Prophetenkönigs mit der Verkündigung der Fürsprache vermengt. In den Versionen, die wir jetzt betrachten wollen, fehlt das Motiv der Korrektur: Muhammads Erniedrigung gleicht in keinerlei Hinsicht der Geste des reumütigen Königs; sie ist vielmehr ein freiwilliger Akt und Bestandteil eines Heilsplans.

Trivium, 29 | 2019 


\section{Schätze bezogen:}

»Dem Gesandten Gottes wurde gesagt: ^Wenn du willst, werden dir die Schätze der Erde in einem Ausmaß gegeben, wie es noch niemand vor dir bekommen hat oder nach dir bekommen wird, ohne dass dein Lohn im Jenseits im Geringsten geschmälert würde.« Er antwortete: >Hebt sie für mich im Jenseits auf.« « ${ }^{104}$

Im Jenseits wird Muhammad etwas bekommen, das größer ist als Salomons Königreich. 'Abd al-Rahmân b. Abî 'Aqîl, der mit Vertretern seines Stammes in einer Delegation zu Muhammad geschickt wurde, erzählt:

„Als wir uns bei ihm vorstellten, war er für uns die verhassteste Person der Welt, aber als wir wieder gingen, war er für uns zum teuersten aller Menschen geworden. Einer von uns sagte: $>\mathrm{O}$ Gesandter Gottes, warum fragst du deinen Herrn nicht nach einem Königreich wie dem von Salomon?« Er lachte und antwortete dann: `Für euren Freund gibt es vielleicht bei Gott etwas Besseres als Salomons Königreich. In Wirklichkeit entsendet Gott niemals einen Propheten, ohne ihm eine Bitte zu gewähren. Jemand verlangt die Welt, und er wird erhört. Jemand verflucht sein Volk, wenn es sich ihm widersetzt, und aufgrund seiner Bitte geht sein Volk unter. Was die Bitte betrifft, die Gott mir gewährt hat, so habe ich sie verborgen, um für meine Gemeinschaft Fürbitte zu leisten (ikhtaba'tuhâ shafấatan li-ummatî).««105

In diesen Überlieferungen wird das "Königtum» nicht ausgeschlagen, sondern verschleiert und aufgeschoben: »Der Prophet [...] wählt [die Knechtschaft] und verschleiert so, um die Universalität seiner letztlichen Bestimmung zu bewahren, seine transzendente und wesentliche innere Realität. «106 Was Muhammad in dieser Welt »verborgen« hat, manifestiert sich in der anderen. Muhammads Fürbitte wird tatsächlich mit seinem "preislichen Rang« (maqâm mahmûd) gleichgesetzt, in dem er dem Koran zufolge wiederauferstanden sein wird. ${ }^{107}$ Einer exegetischen Tradition zufolge ist die Erlangung dieses Ranges der Lohn für die Wahl der Knechtschaft:

"Qatâda hat gesagt: Man hat uns erzählt, dass der Prophet Gottes vor die Wahl gestellt wurde, ob er ein dienender oder ein königlicher Prophet sein wolle, und Gabriel ihm ein Zeichen gegeben habe, sich zu erniedrigen. Gottes Prophet entschied sich also, ein dienender Prophet zu sein, und deshalb wurden ihm zwei Dinge gegeben: dass er der erste wäre, für den sich die Erde öffnen wird, und der erste Fürsprecher. Und diejenigen, die wissen, sind der Meinung, dass der preisliche Rang, von dem Gott sagt, vielleicht erweckt dich dein Herr zu einem preislichen Rang, die Fürbitte am Tag der Auferstehung ist. «108

In diesem eschatologischen Zusammenhang ist das Thema von Muhammads Wahl eng mit dem Nachdenken über sein »Wesen« verknüpft. Tatsächlich besteht das Problem, das sich den Kommentatoren dieses Verses stellt, im Verhältnis der beiden Attribute der »Knechtschaft« ('ubûdiyya) und der »Herrschaft« (rubûbiyya), hier verstanden als »Menschlichkeit« und »Göttlichkeit«. ${ }^{109}$ Zwar bestreiten die von Tabarî untersuchten theologischen Auffassungen, Muhammads Verherrlichung - selbst wenn man sich jenen anschlösse, denen zufolge sie bedeutet, »dass Gott ihn neben sich auf dem Thron sitzen lassen wird « - impliziere, man müsse ihm eine »Herrschaft « zuschreiben. ${ }^{110}$ Das Problem aber war aufgeworfen. Hallâj, ein Zeitgenosse Tabarîs, hatte es in seinen Gedichten offengelegt und sich dafür die beiden Begriffe nâsût (»Menschlichkeit«) und lâhût (»Göttlichkeit«) ausgeliehen, die von arabischen Christen in ihren christologischen Diskussionen gebraucht wurden. ${ }^{111}$

Die Lobpreisung des Dieners ist in der Tat ein zentrales christologisches Thema, ${ }^{112}$ auf dessen Spuren man auch in der Geschichte der Versuchung Jesu in der Wüste stößt. 
Abû Nu'aym scheint sich vom Ende dieser Episode inspirieren zu lassen, wenn er behauptet, dass Muhammad dank seiner Entscheidung für die Knechtschaft von den Engeln bedient wurde und sich darin Salomon überlegen zeigte, der seinerseits von Dschinns bedient wurde. ${ }^{113}$ Die Versuchung Jesu ist eine der Erzählungen des Evangeliums, die die asketische islamische Literatur unter ihre erbaulichen Beispiele aufgenommen hat. ${ }^{114}$ Die Apologeten wiederum beziehen sich in ihrer Polemik gegen die Christen oft auf sie, weil sie in ihr den Beweis sehen, dass Christus nicht Gottes "Sohn«, sondern sein "Diener" ist. ${ }^{115}$ In diesem polemischen Kontext dient die Versuchung Jesu gleichermaßen dazu, Muhammad gegen die Anschuldigung zu verteidigen, er bewirke nie Wunder: Die Versuchung zeige, dass keine Wunder zu bewirken nicht bedeute, dass man nicht die Macht dazu habe. ${ }^{116}$

Die Tatsache, dass die "Knechtschaft« Jesu die Folge einer Wahl ist, hat Fakhr al-Dîn alRâzî in seinem Kommentar zu Vers K 4,172 - »Nimmer ist der Messias zu stolz, ein Diener Allahs zu sein, und nicht auch die nahestehenden Engel« - zu einer interessanten Überlegung angeregt. Râzî zufolge besagt dieser Vers nicht einfach nur, dass Christus (wie auch die Engel) Gott unterworfen und nicht hochmütig ist, sondern dass er, obwohl er über die Macht verfügt (qudra), die er mit seinen Wundern unter Beweis gestellt hat, sich dazu erniedrigt, ein Diener zu sein. ${ }^{117}$ Dieser Gedanke erinnert an den Begriff der Kenosis, jenes im Brief an die Philipper mit der Lobpreisung des Dieners verbundene christologische Thema. Die Vorstellung, dass sich Christus in der Menschwerdung seiner "göttliche[n] Gestalt [...] entäußerte« und "Knechtsgestalt" annahm, ${ }^{118}$ wurde mit jüdischen Spekulationen über die »Beschränkung« der göttlichen Gestalt in Verbindung gebracht, durch die sich Gott aus Barmherzigkeit in Gestalt des Menschen zeigt. ${ }^{119}$ Tor Andrae hat auf die Verwandtschaft der Kenosis mit dem Abflauen der muhammadanischen Realität in der Welt hingewiesen, die Qaysarî, ein Kommentator Ibn 'Arabîs, mit dem Ausdruck tat tîl bezeichnet, was so viel heißt wie »zur Untätigkeit verurteilen, berauben, leeren, auslöschen «. ${ }^{120}$

Ibn 'Arabî artikuliert die Idee der »Selbstbeschränkung" Gottes in Form einer Warnung am Ende einer dichten Meditation darüber, wie der Geist in Jesus "Gestalt annimmt" (tajassada):

»Wenn du die Größe (kabbarta) deines Herrn verkündest, dann mache ihn auf die Weise groß, wie Er selbst es tut, wenn er von sich sagt: ।Und erhaben ist Er hoch über ihre [der Ungerechten] Behauptung!` (K 17,43) Die `Ungerechten` aber sind jene, die Ihn für dessen unwürdig halten, wessen er sich selbst nicht für unwürdig hält, denn Er sagt: `Er erfreute sich der Reue seines Dieners`, ১Er empfängt mit lachendem Gesicht jene, die in sein Haus kommen`, ’Er rühmt sich zusammen mit seinen Engeln der Wallfahrer; und Er sagt auch: \Ich hatte Hunger, und du hast mich nicht genährt.< Denn er hat sich Selbst auf die Ebene seines Dieners herab begeben (anzala nafsahu manzilat 'abdihi). Wenn du Seine Größe verkündest und ihn dabei aus diesen Heimstätten entfernst, dann verherrlichst du Ihn nicht, wie Er es verdient, sondern behandelst ihn als Lügner. $\aleph^{121}$

57 Was lehrt uns das »Hadith der Wahl « aus historischer Sicht? Im »Hadith der Wahl« kommt eine Debatte der Urgemeinde darüber zum Vorschein, wie Muhammad zu charakterisieren ist. Diese Debatte, die sich eher in Typen als in Begriffen artikuliert, orientiert sich an der Polarität der beiden messianischen Figuren des »Königs« und des "Dieners" bzw. "Knechts«. Die islamischen Autoren interessieren sich für diese biblischen Figuren nicht nur mit dem polemischen Ziel, den »Leuten des Buches« zu beweisen, dass ihre Heilige Schrift, recht verstanden, die Ankündigung der Ankunft Muhammads enthält, sondern um Antworten auf Fragen $\mathrm{zu}$ finden, welche sich 
Gläubigen stellen, die seine Prophetie anerkennen. Die Diskussion der Urgemeinde über diese Typologien ist eine Fortsetzung der Debatte um die Interpretation des Messianismus, die das Christentum und das Judentum jahrhundertelang durchzog und die in der ersten islamischen Epoche noch lebendig war. Auch wenn die Identifikation des Messias die drei »Buchreligionen« voneinander trennt, so bleibt doch die nähere Bestimmung seines Wesens und seiner Rolle für sie alle ein umstrittenes Feld. Dass die Kalifen den »königlichen Propheten" bevorzugten, hat seine Parallelen in der byzantinischen politischen Theologie. Dass die alten »Entsagenden" den »dienenden Propheten « bevorzugten, hat wiederum Parallelen in der Aufwertung des asketischen Jesus in monastischen Milieus wie in jüdischen Spekulationen über den »Knecht Messias «. ${ }^{122}$ In den von uns untersuchten Varianten und Interpretationen der Geschichte von der Wahl werden die königlichen Eigenschaften des Propheten abwechselnd abgelehnt, relativiert und eschatologisch interpretiert. Knechtschaft und Königtum erscheinen hier wenn nicht als Gegensätze, so doch zugleich vereint und unterschieden in der Person Muhammads. Die Wahl setzt eine Dualität im Propheten selbst voraus, ja sogar eine Spannung, die den ursprünglichen Quellen des Islams eingeschrieben ist.

\section{BIBLIOGRAPHIE}

\section{Quellen}

'Abd al-Râziq, 'Alî (1959): „L'Islam e le basi del potere«, übers. von E. Panetta, in: Studi politici, 5 (4), S. 216-411.

'Abd al-Razzâq al-San'ânî (1403 H.): Musannaf, hg. von H. al-Rahmân al-A'zamî, Beirut: al-Majlis al-'ilmî bi-Pâkistân - al-Maktab al-islâmî.

Abû Nu'aym (1986): Dalâ’il al-nubuwwa, hg. von M. Ruwwâs Qal'ahjî, Beirut: Dâr al-nafầ'is.

Abû Nu'aym (1974): Hilyat al-awliyâ', Kairo: al-Sa‘âda.

al-Bayhaqî (1988): Dalâ’il al-nubuwwa, Beirut: Dâr al-kutub al-'ilmiyya.

al-Bayhaqî (2003): Shu'ab al-îmân, hg. von 'Abd al-'Alî ‘Abd al-Hamîd Hâmid, Riad: Maktabat alRushd.

al-Bukhârî (1422 H.): Sahîh, Beirut: Dâr Tawq al-najât.

Guillaume, A. (1967): The Life of Muhammad. A Translation of Ibn Ishāa's's Sïrat Rasūl Allāh, Karachi: Oxford University Press.

al-Halabî, Nûr al-Dîn (1427 H.): al-Sîra al-Halabiyya, Beirut: Dâr al-kutub al-'ilmiyya.

Hammâd b. Ishâq (1984): Tarikat al-nabî wa l-subul allatî wajjaha-hâ fîhâ, hg. von Akram al-'Umarî, Beirut. 
Ibn Abî Shayba (1998): al-'Arsh wa mâ ruwiya fîhi li-l-Marwazî, hg. von M. Ibn Khalîfa al-Tamîmî, Riad: Maktabat al-Rushd.

Ibn ‘Arabî (o.J.): al-Futûhât al-makkiyya, Beirut: Dâr al-Sâdir.

Ibn 'Arabî (o.J.): Muhâdarât al-abrâr wa musâmarât al-akhyâr, Beirut: Dâr al-Sâdir.

Ibn 'Asâkir (1995): Târîkh madînat Dimashq, hg. von 'Umar b. Gharâma al-'Amrawî, Beirut: Dâr alfikr.

Ibn Hajar al-'Asqalânî (1379 H.): Fath al-Bârî sharh Sahîh al-Bukhârî, Beirut: Dâr al-ma'rifa.

Ibn Hishâm/Ibn Ishâq (1955): al-Sîra al-nabawiyya, hg. von M. al-Saqqâ u. a., Kairo: Mustafâ al-Bâbî al-Halabî.

Ibn Ishâq (1978): Sîrat Ibn Ishâq (Kitâb al-siyar wa l-maghâzî), hg. von S. Zakkâr, Beirut: Dâr al-fikr. Ibn Ishâq (2004): Das Leben des Propheten, übers. und bearb. von G. Rotter, Kandern: Spohr.

Ibn Ishâq (2017): Die Sira, das Leben des Propheten Mohammed, bearbeitet von Abu Mohammed Abd el-Malik Ibn Hischam. Ungekürzte Ausgabe, nach der Übersetzung von Dr. Gustav Weil. Hg. von Ralf Lunnebeck, München: Arnulf Blecken.

Ibn al-Mubârak, 'A. (o.J.): al-Zuhd wa al-raqâ’iq, hg. von H. al-Rahmân al-A'zamî, Beirut: Dâr alkutub al-'ilmiyya.

Ibn Sa'd (1990): al-Tabaqât al-kubrâ, hg. von 'Abd al-Qâdir Ahmad 'Atâ', Beirut: Dâr al-kutub al-'ilmiyya.

Ibn Taymiyya (o.J.): »Qâ‘ida fî'l-khilâfa wa'l-mulk«, in: ‘A.-R. al-'Âsîmî al-Najdî (Hg.), Kutub wa rasẩil wa fatâwâ Shaykh al-Islâm Ibn Taymiyya, Bd. XXXV, o.O., S. 18-35.

Massignon, L. (1931): »Le Dîwân d'al-Ḥallâj. Essai de reconstitution, édition et traduction «, in: Journal Asiatique, 218, S. 1-158.

al-Mâwardî (1409 H.): A'lâm al-nubuwwa, Beirut: Dârwamaktabat al-hilâl.

al-Mu'âfâ b. 'Imrân al-Mawsilî (1999): al-Zuhd, hg. von ‘Âmir Hasan Sabrî, Beirut: Dâr al-bashâ’ir al-islâmiyya.

al-Munâwî 'Abd al-Ra'ûf (1391 H.): Fayd al-qadîr sharh 'alâ al-Jâmi' al-saghîr, Beirut: Dâr al-ma'rifa. al-Qastallânî (o.J.): al-Mawâhib al-laduniyya bi-l-minah al-Muhammadiyya, Kairo: al-Maktaba altawfîqiyya.

al-Râzî (2000): Traité sur les noms divins, übers. von M. Gloton, Beirut: Éditions Al Bouraq.

al-Râzî, Fakhr al-Dîn (1933): al-Tafsîr al-kabîr (Mafâtîh al-ghayb), hg. von M. Muhyî l-Dîn, Kairo: alMatba'a al-misriyya.

al-Tabarî, 'Alî ibn Sahl Rabban (2016a): »al-Dîn wa-al-dawla«, in: R. Ebied u. D. Thomas (Hg.): The Polemical Works of 'Alī al-Tabarī, Leiden: Brill.

al-Tabarî, 'Alî ibn Sahl Rabban (2016b): »al-Radd 'alâ al-nasârâ«, in: R. Ebied u. D. Thomas (Hg.), The Polemical Works of 'Alī al-Tabarī, Leiden: Brill.

al-Tabarî, Muhammad ibn Jarîr (1405 H.): Jâmi' al-bayân fi tafsîr al-Qur'ân, Beirut: Dâr al-Fikr. 


\section{Studien}

Addas, C. (2015): La maison muhammadienne. Aperçus de la dévotion au Prophète en mystique musulmane, Paris: Gallimard.

Andrae, T. (1917): Die Person Muhammeds in Lehre und Glauben seiner Gemeinde, Upsala: Appelbergs Boktryckeri Aktiebolag (Archives d'Études Orientales, Bd. XVI).

Arnaldez, R. (1986): »Lāhūt and nāsūt«, in: Encyclopaedia of Islam 2, Bd. V, S. 611-614.

Bobzin, H. (2010): »The `Seal of the Prophets`. Towards an Understanding of Muhammad's Prophethood«, in: A. Neuwirth, N. Sinai und M. Marx (Hg.): The Qur'ān in Context. Historical and Literary Investigations into the Qur'ānic Milieu, Leiden: Brill, S. 565-584.

Borrut, A. (2011): Entre mémoire et pouvoir. L'espace syrien sous les derniers Omeyyades et les premiers Abbassides, Leiden: Brill.

Brague, R. (2005): La loi de Dieu. Histoire philosophique d'une alliance, Paris: Gallimard.

Brockopp, J. E. (2004): »Servants«, in: J. D. McAuliffe (Hg.): Encyclopaedia of the Qur'ān, Leiden: Brill, Bd. 4, S. 576-580.

Chialà, S. (Hg.) (2009): I detti islamici di Gesù, übers. von I. D. Francesco, Mailand: Mondadori.

Chodkiewicz, M. (1997): »The Banner of Praise«, in: S. Hirtenstein (Hg.): Praise, Oxford: Muhyiddin Ibn Arabi Society, S. 45-58.

Cook, M. (2011): »Did the Prophet Muhammad Keep Court?«, in: A. Fuess und J.-P. Hartung (Hg.): Court Cultures in the Muslim World. Seventh to Nineteenth Centuries, London u. New York: Routledge, S. 2-29.

Crone, P. (2004): God's Rule. Government and Islam, New York: Columbia University Press.

Crone, P. (2011): »Angels versus Humans as Messengers of God«, in: P. Townsend u. M. Vidas (Hg.): Revelation, Literature and Community in Late Antiquity, Tübingen: Mohr Siebeck, S. 315-336.

Dagron, G. (1996): Empereur et prêtre. Étude sur le «césaropapisme» byzantin, Paris: Gallimard.

Déclais, J.-L. (1999): David raconté par les musulmans, Paris: Cerf.

Déclais, J.-L. (2001): Un récit musulman sur Isaïe, Paris: Cerf.

Demiri, L. (2013): Muslim Exegesis of the Bible in Medieval Cairo. Najm al-Din al-Ṭüf’'s (d. 716/1316)

Commentary on the Christian Scriptures, Leiden: Brill.

Gilliot, C. (1990): Exégèse, langue et théologie en islam. L'exégèse coranique de Tabari, Paris: Vrin.

Gril, D. (2000): »Melchisédech en islam ou les raisons d'une absence«, in: Autour de Melchisédech. Mythe, réalités, symbole, Chartres: Association des Amis du Centre Médiéval Européen de Chartres, S. $61-68$.

Gril, D. (2007): »Le saint et le maître ou la sainteté comme science de l'Homme, d'après le Rûh alquds d'Ibn 'Arabî«, in: N. Amri u. D. Gril (Hg.): Saint et sainteté dans le christianisme et l'islam. Le regard des sciences de l'homme, Paris: Maisonneuve et Larose, S. 55-106.

Gruber, C. (2010): The Ilkhanid Book of Ascension. A Persian-Sunni Devotional Tale, London: Tauris.

Gruber, C. (2014): »Images«, in: C. Fitzpatrick u. A. H. Walker (Hg.): Muhammad in History, Thought, and Culture. An Encyclopedia of the Prophet of God, Santa Barbara: ABC-Clio, S. 286-294. 
Hillenbrand, R. (2014): »Muhammad as Warrior Prophet. Images from the World History of Rashid al-Din«, in: C. Gruber u. A. Shalem (Hg.): The Image of the Prophet between Ideal and Ideology, Berlin: Walter de Gruyter, S. 65-75.

Hultgren, S. (2002): Narrative Elements in the Double Tradition. A Study of Their Place within the Framework of the Gospel Narrative, Berlin: de Gruyter.

Kazimirski, A. d. B. (1860): Dictionnaire Arabe-Français, Paris: Maisonneuve.

Kister, M. J. (1986): »The Massacre of the Banū Qurayẓa. A Re-Examination of a Tradition«, in: Jerusalem Studies in Arabic and Islam, 8, S. 61-96.

Lane, E. W. (1863-1893): Arabic-English Lexicon, 8 Bde., London: Williams and Norgate.

Madelung, W. (1997): The Succession to Muhammad. A Study of the Early Caliphate, Cambridge: Cambridge University Press.

Marsham, A. (2009): Rituals of Islamic Monarchy. Accession and Succession in the First Muslim Empire, Edinburgh: Edinburgh University Press.

Mourad, S. A. (2004): „Christian Monks in Islamic Literature. A Preliminary Report on Some Arabic Apophthegmata Patrum «, in: Bulletin of the Royal Institute for Inter-Faith Studies, Bd. 6, Nr. 2, S. 81-98.

Motzki, H. (2010): Analysing Muslim Tradition. Studies in Legal, Exegetical and Maghâzî Hadîth, Leiden: Brill.

Nagel, T. (2008): Mohammed. Leben und Legende, München: Oldenbourg.

Pedersen, J. (1993), »Minbar«, Encyclopaedia of Islam 2, Bd. VII, S. 73-76.

de Prémare, A.-L. (1990): »Prophétisme et adultère, d'un texte à l'autre«, in: Revue du monde musulman et de la Méditerranée, Bd. 58, Nr. 1, S. 101-135.

de Prémare, A.-L. (2002): Les fondations de l'islam. Entre écriture et histoire, Paris: Seuil.

Rubin, U. (1995): The Eye of the Beholder. The Life of Muhammad as Viewed by the Early Muslims, Princeton: The Darwin Press.

al-Qâdî, W. (1988): »The Term khalīfa in Early Exegetical Literature«, in: Die Welt des Islams, 28, S. 392411.

Reynolds, G. S. (2004): Muslim Theologian in the Sectarian Milieu. 'Abd al-Jabbâr and the 'Critique of Christian Origins', Leiden: Brill.

Reynolds, G. S. (2014): »Gabriel«, in: Encyclopaedia of Islam, Three, Brill Online.

Schäfer, P. (2012): The Jewish Jesus. How Judaism and Christianity Shaped Each Other, Princeton $\mathrm{u}$. Oxford: Princeton University Press.

Shoemaker, S. J. (2012): The Death of a Prophet. The End of Muhammad's Life and the Beginnings of Islam, Philadelphia: University of Pennsylvania Press.

Sizgorich, T. (2007): »'Do Prophets Come with a Sword?^ Conquest, Empire, and Historical Narrative in the Early Islamic World«, in: American Historical Review, Bd. 112, Nr. 4, S. 993-1015.

Sourdel, D. (1997): "Kadị̂ib«, Encyclopaedia of Islam 2, Bd. 4, S. 377-378.

Stroumsa, G. G. (1983): »Form(s) of God. Some Notes on Metatron and Christ: For Shlomo Pines«, in: The Harvard Theological Review, Bd. 76, Nr. 3, S. 269-288. 
Tanındı, Z. (1984): Siyer-i Nebî. Islâm tasvir sanatında Hz. Muhammed'inhayatı, o.O.: HürriyetVakfıYayınları.

Wansbrough, J. (2004): Quranic Studies. Sources and Methods of Scriptural Interpretation, New York: Prometheus Books.

Wensinck, A. J. (1922): „The Refused Dignity«, in: T. W. Arnold u. R. A. Nicholson (Hg.): A Volume of Oriental Studies Presented to Edward G. Browne on his 60th Birthday, Cambridge: Cambridge University Press, S. 491-499.

Widengren, G. (1955): Muhammad, The Apostle of God, and His Ascension (King and Saviour V), Uppsala u. Wiesbaden: Lundequistska u. Harrassowitz.

\section{NOTES}

1. Mit diesem Ausdruck beschreibt Ibn 'Arabî (o.J.), Muhâdarât, Bd. II, S. 141, das Hadith, von dem er zwei Varianten bringt.

2. Brockopp (2004), S. 577.

3. Hultgren (2002), S. 95-127.

4. 'Abd al-Râziq (1959), S. 391.

5. Brague (2005), S. $70 \mathrm{ff}$.

6. Crone (2004), S. 10-16.

7. Ibn Hishâm/Ibn Ishâq (1955), Bd. I, S. 295-298; Guillaume (1967), S. 133 f.; Ibn Ishâq (2017), S. 115-117 (ergänzt). [Für die deutsche Fassung des vorliegenden Aufsatzes wurden die deutsche Teilübersetzung des Werks von Ibn Ishâq (2004) sowie die vollständige Übersetzung Ibn Ishâq (2017) herangezogen, die aber ebenfalls nicht alle zitierten Passagen enthält und für die hiesigen Zwecke gelegentlich unterschiedlich stark modifiziert werden muss; A.d.Ü.].

8. Vgl. K 6,50; 17,92-93; $25,7$.

9. al-Halabî (1427 H.), Bd. I, S. 436; Ibn Hishâm/Ibn Ishâq (1955), Bd. I, S. 297. Zur koranischen Debatte über die menschliche oder engelhafte Natur des Boten vgl. Addas (2015); Crone (2011).

10. Matthäus 4,1-11; vgl. Wansbrough (2004), S. 67.

11. Ibn Ishâq (1978), S. 209.

12. Ebd.; vgl. 4. Mose 16, 35.

13. Vgl. Lukas 9, 54-55.

14. Ibn Hishâm/Ibn Ishâq (1955), Bd. I, S. 564; Ibn Ishâq (2017), S. 243; Guillaume (1967), S. 266.

15. Wansbrough (2004), S. 70 f.; de Prémare (1990).

16. Vgl. hierzu die Erklärung von Ibn Taymiyya (o.J.), S. 34.

17. Bobzin (2010); Sizgorich (2007).

18. Guillaume (1967), S. 678, übersetzt »long life here followed by Paradise«.

19. Ibn Hishâm/Ibn Ishâq (1955), Bd. II, S. 642; Ibn Ishâq (2004), S. 252 (Übers. mod.); Guillaume (1967), S. 678.

20. Ibn Hishâm/Ibn Ishâq (1955), Bd. II, S. 649; Ibn Ishâq (2017), S. 598 (Übers. mod.); Guillaume (1967), S. 679.

21. Ibn Hishâm/Ibn Ishâq (1955), Bd. II, S. 651 f., 655; Ibn Ishâq (2017), S. 601; Guillaume (1967), S. 680,682 .

22. Jesaja 9, 6-7; 45, 1-3; Daniel 2, 44.

23. Tabarî (2016a), S. 355 (Jes 9, 6) u. 415 (Dan 2, 44).

24. Bukhârî (1422 H.): k. al-jihâd wa l-siyar, Nr. 2815.

25. Ibn Hishâm/Ibn Ishâq (1955), Bd. II, S. 655 f.; Ibn Ishâq (2017), S. 601 (Übers. mod.); Guillaume (1967), S. 682 f.; Déclais (1999), S. 285 f. 
26. Ibn Sa'd (1990), II, S. 208.

27. Shoemaker (2012), S. 90-94, $114 \mathrm{ff}$.

28. Ibn Sa‘d (1990), Bd. II, S. 198; Déclais (1999), S. 282-288.

29. Matthäus 16, 22-23.

30. Déclais (1999), S. 49; de Prémare (2002), S. 168 ff., 418.

31. Bayhaqî (1988), Bd. I, S. 335, 337. Die gleiche Lektion wird übrigens auch 'Â'isha erteilt: Ibn Sa‘d (1990), Bd. I, S. 288.

32. Ibn Sa'd (1990), Bd. I, S. $270 \mathrm{ff}$.

33. Abû Nu'aym (1986), Bd. I, S. 72; Qastallânî (o.J.), Bd. II, S. 549.

34. Déclais (2001), S. 57-62, 131-138; Rubin (1995), S. 30-35.

35. Vgl. Jesaja 53,7; 1 . Petrus $2,23$.

36. Ibn Sa'd (1990), Bd. I, S. 271. Ich verwende hier die Übersetzung von Déclais (2001), S. 135. Vgl. ebd., S. 73, die Beschreibung des Charakters (khuluq) des letzten Propheten in der Paraphrase Jesajas durch Ibn Ishâq.

37. Ibn Satd (1990), Bd. I, S. 274, 280.

38. Ebd., S. 274.

39. Die Nachfolger (tâbi ûn) sind die Autoritäten in der Generation nach den Gefährten.

40. Ibn Sa'd (1990), Bd. I, S. 279.

41. Vgl. auch Ibn Hajar al-'Asqalânî (1379 H.), Bd. IX, S. 541: »Man bot dem Propheten einen Schafskäse an, und er hockte sich nieder, um ihn zu essen. Ein Beduine fragte ihn: Was ist das für eine Haltung? Er sagte: Gott hat aus mir einen großherzigen Diener gemacht und keinen unverschämten Tyrannen (jabbâr 'anîd: vgl. K 11,59)«; Ibn 'Arabî (o.J.): Futûhât, Bd. IV, S. 499 (bâb al-was âyâ: lâ ta'kul akl al-jabbârîn muttaki'an).

42. [Die dt. Übersetzung des Korans von Max Henning hat an diesen Stellen: »Recken« $(5,22)$, »widerspenstigen Gewaltigen« (11,59) und »trutzige Rebell« $(14,15) ;$ A.d.Ü.]

43. Al-Râzî (2000), S. 355.

44. Jesaja 42,13; Tabarî (2016a), S. 350 f.

45. Psalmen 45,4; Qastallânî (o.J.), Bd. II, S. 555; Tabarî (2016a), S. 344.

46. Tabarî (2016a), S. 345, 351.

47. Qastallânî (o.J.), Bd. II, S. 555.

48. Al-Râzî (2000), S. 356.

49. Tabarî (2016a), S. 405.

50. Ibn Sa'd (1990), Bd. I, S. 279.

51. Ebd., S. 280.

52. Ebd. Muhtafiz ist ein Synonym für mustawfiz; vgl. Lane (1863-1893), Bd. II, S. 604, und die folgende Anm.

53. Ibn Sa'd (1990), Bd. I, S. 288. Vgl. die aus dem Qâmûs al-muhît gezogene Erklärung von Lane (1863-1893), Bd. VIII, S. 2962: »Ich esse nicht in einer festen - oder bequemen - Sitzhaltung, mit übereinandergeschlagenen Beinen oder in einer ähnlichen Haltung, die sich für die meisten Mahlzeiten eignet: denn er pflegte beim Essen in der Hocke zu sitzen, mit geraden Oberschenkeln, um sich jederzeit erheben (mustawfiz) zu können.« Ibn Hajar al-'Asqalânî (1379 H.), Bd. IX, S. 541, bezieht sich auf lexikographische Diskussionen über den Ausdruck muttaki' und Meinungsverschiedenheiten über den - verbotenen oder verabscheuungswürdigen - rechtlichen Status dieser Art und Weise, sich hinzusetzen. Einer Stimme zufolge sei dieser Status ein Vorrecht des Propheten und keine Sunna.

54. Ibn Sa'd (1990), Bd. I, S. 288.

55. Ebd. - Diese Überlieferung wurde von einem Schüler Zuhrîs weitergegeben, Ma'mar ibn Râshid al-Azdî (gest. 153/770). Dessen Sammlung von Überlieferungen wurde wiederum von seinem Schüler 'Abd al-Razzâq al-San'ânî (gest. 211/826) in seiner Musannaf für die Nachwelt erhalten, s. Motzki (2010), S. 4-12. Vgl. Ma'mar ibn Râshid: al-Jâmi', in: 'Abd al-Razzâq al-San'ânî 
(1403 H.), Bd. X, S. 417. Die Tradition wird in alten Sammlungen von Überlieferungen zur zuhd wieder aufgenommen, etwa denen von 'Abdallâh b. al-Mubârak (gest. 180/797): Ibn al-Mubârak (o.J.), S. 264 f., und von al-Mu'âfâ b. 'Imrân al-Mawsilî (gest. 185/801): al-Mu'âfâ b. 'Imrân alMawsilî (1999), S. 239. Die isnâd von al-Mu'âfâ b. 'Imrân geht auf Sa'îd ibn Jubayr (gest. 95/714) zurück, den tâbi von Kufa, der berühmt war für seine Teilnahme an einem Aufstand gegen den Umayyaden-Herrscher al-Hajjâj und für die Martern, die dieser ihm zufügte: Motzki (2010), S. 446. Ibn Sa'd zitiert in seiner isnâd Ma'mar und Ibn al-Mubârak. Vgl. auch die Variante, die auf dem Umweg über 'Â'isha direkt auf den Propheten zurückgehen soll: Ibn Sa'd, Bd. I, S. 288.

56. Vgl. Lukas 22,27: »Welcher von beiden ist größer: wer bei Tisch sitzt oder wer bedient? Natürlich der, der bei Tisch sitzt. Ich aber bin unter euch wie der, der bedient.«

57. Ibn Hajar al-'Asqalânî (1379 H.), Bd. IX, S. 542. In der Bibel wird der von den Propheten angeprangerte Brauch, im Liegen zu essen (vgl. Amos 6,4), mit der persischen Monarchie in Verbindung gebracht (Ester 1,6; 7,8).

58. 'Abd al-Razzâq al-San'ânî (1403 H.), Bd. III, S. 184.

59. Ebd.

60. Gemeint ist wahrscheinlich 'Atâ' b. Abî Rabâh (gest. 115/733); vgl. Motzki (2010), S. 12.

61. 'Abd al-Razzâq al-San'ânî (1403 H.), Bd. III, S. 183 f.

62. Zu der Tatsache, dass Muhammad auf seinem Minbar saß und auf einen Stab ('asâ) aufgestützt predigte, vgl. Ibn Sa'd (1990), Bd. I, S. 192-196. Vgl. auch ebd., S. 185: Muhammad hielt die Freitagspredigt mit einem »Zepter« (mikhsara) in der Hand. Die mikhsara war ein Zeichen der Königswürde, das auch vom khatîb genutzt wurde: vgl. Lane (1863-1893), Bd. II, S. 749.

63. Nach den von 'Abd al-Razzâq al-San'ânî (1403 H.), Bd. III, S. 182, 187-190 festgehaltenen Überlieferungen geht die Praxis, auf dem Minbar sitzend zu predigen, weder auf den Propheten noch auf die "rechtgeleiteten« Kalifen zurück, die aufrecht stehen blieben, sondern wurde von Mu'âwiya eingeführt; alternativ führt man diesen Brauch auf die zweite Phase von 'Uthmâns Kalifat zurück. Vgl. auch Cook (2011).

64. Sourdel (1997); Pedersen (1993); Widengren (1955), S. 98-102, 154 f. Vgl. auch Ibn Sa‘d (1990), Bd. II, S. 207: Nachdem er den Treueeid entgegengenommen hat, setzt sich (istawâ) Abû Bakr auf den minbar des Gesandten. Derselbe Ausdruck wird im Hinblick auf Muhammad verwendet: Ibn Sa'd (1990), Bd. II, S. 176.

65. Marsham (2009), S. 109, 314.

66. Widengren (1955), S. $154 \mathrm{f}$.

67. Hammâd b. Ishâq (1984), S. 9 ff.

68. K 27,16. Vgl. Madelung (1997), S. 360 f.

69. Marsham (2009), S. 6 f., 10, 123f., 138 f.; Borrut (2011), S. 217-228.

70. S. die Verweise auf Juwaynî, Mâwardî und auf die Ikhwân al-Safâ' (Brüder der Reinheit) in Crone (2004), S. 11.

71. Gruber (2014), S. 287.

72. Die zuhd (»der [weltliche] Verzicht«) ist das Modell von Frömmigkeit, das die fromme Tradition in den ersten Jahrhunderten des Islams beherrscht hat. Wer es befolgt, wird »Verzichtender« (zâhid) genannt.

73. al-Qâdî (1988).

74. Vgl. 2. Samuel 12.

75. Paris, BNF, Ms. grec 139, f. 136v. Das Bild ist einzusehen unter http://mandragore.bnf.fr/. Vgl. Dagron (1996), S. 129-138. Das Motiv der Prosternation steht in Zusammenhang mit der Haltung Muhammads in einer der Überlieferungen über seine Essgewohnheiten. Nach dieser Version berichtete 'Â'isha: „Man brachte dem Gesandten Gottes zu essen. Ich sagte zu ihm: `Warum isst du nicht aufgestützt? So hättest du es bequemer! Daraufhin beugte er den Kopf so tief hinunter, dass er mit seiner Stirn fast den Boden berührte. `Nein<, sagte er mir, >ich esse, wie ein Diener isst, indem ich mich hinsetze.« Ibn 'Asâkir (1995), Bd. IV, S. 73. 
76. Dagron (1996), S. 120 f., 127 f.

77. Ebd., S. 118, 134-137.

78. K 38,24 u. 26.

79. $38,17-20$.

80. Insbesondere Mu'âwiya, genannt amîr al-mu'minîn und »Diener Gottes«: Nagel (2008), S. 681. Zur Demut der ersten vier Kalifen: Mâwardî (1409 H.), S. 220. Vgl. zu diesem Thema Wensinck (1922).

81. Marsham (2009), S. 138.

82. Dagron (1996), S. 71; Crone (2004), S. 45 f.

83. Vgl. Déclais (1999), S. 25.

84. Ibn Taymiyya (o.J.), S. 21.

85. Ebd., S. 34.

86. Ebd., S. 27.

87. Ibn Khaldûn rehabilitiert gleichermaßen die Umayyaden, indem er ihre Parallele zu David und Salomon unterstreicht: vgl. Borrut (2011), S. 221.

88. Ibn Taymiyya (o.J.), S. 34.

89. Mâwardî (1409 H.), S. 159 f.

90. Ebd., S. 159, 222 (innamâ yakhtașs 'afwuhu bi-haqq nafsihi); vgl. auch die von Ibn Sa'd (1990), Bd. I, S. 275 berichtete Überlieferung 'Â'ishas.

91. Qastallânî (o.J.), Bd. II, S. 549.

92. Der Ausdruck hils bezeichnet die Decke, die man unter den Kamelsattel legt, die Leibwäsche, die man unter der Kleidung trägt, oder einen Teppich; die Wendung fulân ka-l-hils al-mulqâ bedeutet nach Kazimirski (1860), Bd. I, S. 479: „Einer, der wie eine Matte zu Boden geworfen wird, ist ein Nichts«. Vgl. auch Lane (1863-1893), Bd. II, S. 630. Bayhaqî (2003), Bd. I, S. 312, bringt die Variante: ka'annahu hils lâti', "wie ein Stück Wäsche am Boden kleben«.

93. Ibn al-Mubârak (o.J.), Bd. I, S. 73.

94. Bayhaqî (2003), Bd. I, S. 315. Vgl. auch Ibn Abî Shayba (1998), S. 461 f.

95. Nach Ibn 'Arabî nimmt Gabriel in dieser Erzählung effektiv den Platz des Herrn ein: Gril (2007), S. 89, 96.

96. Gruber (2010), S. 77, 96.

97. Reynolds (2014).

98. Ibn Ishâq (1978), Bd. I, S. 297.

99. Ibn Hishâm/Ibn Ishâq (1955), Bd. II, S. 233; Ibn Ishâq (2017), S. 401. - Mâwardî (1409 H.), S. 222, merkt an, dass Muhammad in diesem Fall seiner Neigung zur Barmherzigkeit nicht folgen konnte, weil er einem göttlichen Gebot folgen musste; vgl. auch Kister (1986), S. 69. Manche Überlieferungen unterstreichen, dass der Prophet vom plötzlichen Eingreifen Gabriels erschrocken war, oder ergänzen, dass er vergeblich einen Aufschub von einigen Tagen erbat: vgl. al-Halabî (1427 H.), Bd. II, S. 441.

100. Munâwî (1391 H.), Bd. I, S. 147, Anm. 158.

101. Vgl. K 66,4 .

102. Vgl. die Miniatur, die Gabriel zeigt, wie er den byzantinischen Kaiser Basileios I. zum Herrn der Welt krönt: Dagron (1996), S. 203 und Abb. 7. Diese wäre zu vergleichen mit der Rolle des Engels in den Miniaturen, die Muhammad als Krieger darstellen: Hillenbrand (2014), Tafeln $11 \mathrm{u}$. 12.

103. Hammâd b. Ishâq (1984), S. 48 f.

104. Hammâd b. Ishâq (1984), S. 46; Mâwardî (1409 H.), S. 218.

105. Hammâd b. Ishâq (1984), S. 54. - Der Empfang von Delegationen arabischer Stämme durch Muhammad ist in der Sîra eine weitere Gelegenheit, um zu überprüfen, ob er ein Prophet oder ein König ist; vgl. Guillaume (1967), S. 638 f.

106. Gril (2000), S. 68. 
107. K 17,79 .

108. Tabarî (1405 H.), Bd. XV, S. 145, über K 17,79 .

109. [Zu diesen beiden Eigenschaften des Propheten vgl. den Beitrag von D. Gril im vorliegenden Band.]

110. Tabarî (1405 H.), Bd. XV, S. 145: wa-lâ fî iq âd Muhammad s. mûjiban lahu sifat al-rubûbiyya wa-lâ makhrajahu min sifat al-'ubûdiyya li-rabbihi. Zu Muhammads Inthronisierung vgl. Gilliot (1990), S. 250-254. Zur Interpretation 'Ibn 'Arabîs vgl. Chodkiewicz (1997). Eine Miniatur, die Muhammad auf einem himmlischen Thron sitzend zeigt, findet sich bei Tanındı (1984), Tafel 31.

111. Massignon (1931), S. 41; Arnaldez (1986).

112. Vgl. Philipper 2,6-9.

113. Abû Nu'aym (1986), Bd. I, S. 600 ff. Vgl. Matthäus 4,11; Lukas 11,31.

114. Abû Nu'aym (1974), Bd. IV, S. 12, 54; Chialà (2009), S. 39; Mourad (2004), S. 89 f.

115. Tabarî (2016b), S. 71, 103-105; Demiri (2013), S. 143 ff.; Reynolds (2004), S. 160 f., 199 f.

116. Tabarî (2016a), S. 443 ff.

117. Râzî (1933), Bd. II, S. 221f., zu 2,30.

118. Philipper 2, 6-7.

119. Stroumsa (1983), S. 281-284.

120. Andrae (1917), S. 350ff.; Kazimirski (1860), Bd. II, S. 288.

121. Ibn 'Arabî (o.J.): Futûhât, Bd. II, S. 405.

122. Vgl. Schäfer (2012), S. 236-264.

INDEX

Mots-clés : Muhammad, prophète roi, prophète serviteur

Schlüsselwörter : Muhammad, königlicher Prophet, dienender Prophet

\section{AUTEURS}

\section{SAMUELA PAGANI}

Samuela Pagani ist Professorin für arabische Sprache und Literatur an der Università del Salento in Lecce (Italien). Nähere Informationen finden Sie hier. 